THURSDAY, JULY $27,187 \mathrm{I}$

\section{MR. CROOKES ON THE "PSYCHIC" FORCE}

ITH a boldness and honesty which deserve the greatest respect, Mr. Crookes has come forward as an investigator of those mysterious phenomena which have now been so long before the public that it is unnecessary to name them, more especially as their generally received name is very objectionable.

Two things have contributed to retard our knowledge of these strange events. In the first place, until lately few men of name have been associated with their occurrence, so that outsiders have not had the facts put before them in a proper manner. In the next place, we are inclined to endorse the remark of Mr. Crookes, that men of science have shown too great a disinclination to investigate the existence and nature of these alleged facts, even when their occurrence had been assetted by competent and credible witnesses,

Before adverting to the results obtained by Mr. Crookes, a few words may be said about our mode of procedure in accepting testimony.

Let us suppose that a man comes before us as a witness of some strange and unprecedented occurrence. Here it is evident that we are not entitled to reject his testimony on the ground that we cannot explain what he has seen in accordance with our preconceived views of the universe, even although these views are the result of a long experience ; for by this means we should never arrive at anything new. Our first question is manifestly one regarding the man's moral character. Is he an honest and trustworthy man, or is he trying to cleceive us?

Let us assume that we have convinced ourselves of his honesty; we are then bound to believe that he thought he saw what he described to us; not necessarily, however, that the occurrence which he described actually took place. Convinced, already, that he is not deceiving us, we next question whether he may not be deceived himself. Let us, however, assume that, upon investigation, the circumstances are such that collusion of any kind is out of the question, and that the man is neither trying to deceive us, nor that it is possible that he himself can have been deceived by others. Even yet we have an alternative in our judgment of the event. The phenomenon may be subjective rather than objective, the result of an action upon the man's brain rather than an outstanding reality. For nothing is more certain than the occasional occurrence of such strange impressions; and the cat or the dog or the skeleton by which the patient is haunted is frequently recognised even by himself as having no external existence. Of late years we have been able to produce instances of this depraved consciousness almost at will. The author of these remarks considers it certain that the electro-biologist has frequently caused them. The unimpeachable character of the patient, combined with the fact that he has sometimes pronounced water to be wine, or a snow storm to be taking place in a room, can only be accounted for on the supposition that he has been put into a peculiar state, during which his evidence of events is utterly worthless. But beyond the bare fact, we know next to nothing of the laws that regulate this action, nor can we tell under what conditions one man is capable of influencing another, or whether a man or body of men may not be capable of influencing themselves.

To come now to the class of events which Mr. Crookes has witnessed. It is greatly to his credit that he has come forward so frankly and honestly; and since he has begun to investigate the peculiar class of facts, we are sure that he will consider it his duty to continue the investigation in such a way as to convince those men of science who may not themselves be able to take up the question-outsiders in fact. Mr. Crookes will, we are sure, not object to a few critical remarks honestly made with the sole view of finding out the truth, and we would therefore express a wish that, in order to facilitate operations the experiments should in future be conducted by only by such men as Mr. Crookes himself, and that it should always be absolutely superfluous to investigate whether machinery, apparatus, or contrivance of any sort, be secreted about the persons present. We should thus start from a higher platform, and the investigation would gain in simplicity, although perhaps something might be lost in the marked nature of the results obtained.

Allowing, however (as we are disposed to allow), that things of an extraordinary nature are frequently witnessed on such occasions, yet we are by no means sure that these constitute external realities. The very fact that the results are uncertain, and that, as far as we know, they have never yet been obtained in broad daylight before a large unbiassed audience, would lead us to suspect that they may be subjective rather than objective, occurring in the imaginations of those present rather than in the outward physical world. Nor can this doubt be removed by any precision of apparatus ; for what avails the most perfect instrument as long as we suspect the operator to be under a mental influence of the nature, it may be, of that which is witnessed in electro-biological experiments? The problem is, in fact, one of extreme difficulty, and we do not see how it admits of proof, provided the influence cannot be exerted in broad daylight and before a large audience. There is, however, a cognate phenomenon which admits of easy proof. We allude to clairvoyance, and have in our mind at the present moment a man of science who if not himself a clairvoyant has yet the power to command the services of one who is. Now, were he at once to communicate to a journal such as NATURE, in cipher if necessary, the knowledge derived through the influence, giving the proof afterwards when obtained in an ordinary manner, the public would soon be in a position to judge whether there is any truth in the influence or not.

It is, in fact, somewhat hard upon the writer of these remarks and some others who are disposed to allow the possibility of something of this nature, but have not the opportunity of investigating it, that those who have will not satisfy the public with a convincing proof.

B. STEWART

\section{TYNDALL'S FRAGMENTS OF SCIENCE}

Fragments of Science for Unscientific People. By Prof.

Tyndall, LL.D., F.R.S. (London: Longmans: 187r.)

THIS volume is a reprint of a number of detached essays, lectures, and reviews, by Prof. Tyndall, pubm lished at various times and in various places during the last ten years. Besides a few shorter pieces collected at 